\title{
A Study on Schema Theory-based Listening Teaching Mode for English Majors
}

\author{
Xiaoli Bao ${ }^{1}$ \\ ${ }^{1}$ School of Foreign Language, Inner Mongolia University for Nationalities, Tongliao, Inner Mongolia, China \\ Correspondence: Xiaoli Bao, School of Foreign Language, Inner Mongolia University for Nationalities, \\ Tongliao, Inner Mongolia, China. E-mail: nmbaoxiaoli@163.com
}

Received: May 30, 2016 Accepted: June 16, 2016 Online Published: July 13, 2016

doi:10.5539/ijel.v6n4p207 URL: http://dx.doi.org/10.5539/ijel.v6n4p207

\begin{abstract}
Based on scheme theory, this article aims to investigate the listening teaching mode for English majors under the direction of scheme theory. Research results show that listening teaching which focuses on background knowledge can effectively enhance students' listening comprehension ability. Scheme-based listening teaching has a significant influence on the performance of different levels of English majors.
\end{abstract}

Keywords: schema theory, background knowledge, mode of listening teaching, listening strategies

\section{Introduction}

Listening comprehension ability is a most important language skill. As an input skill, listening comprehension ability takes a very important position in language teaching. However, listening comprehension is often the most difficult skill to master and listening teaching has also become a weak link in language teaching. That is due to one important aspect: English language learners and teachers put too much emphasis on the effects of language knowledge. The language knowledge includes pronunciation, vocabulary and grammar etc. In the listening process, the background knowledge of listeners is as important as the language knowledge. The learners' culture background knowledge mentioned here is the background schema from the perspective of cognitive psychology.

Schema theory is research hotspot of cognitive science, and it is initially used in the research of reading. Later, the foreign scholars applied it to the listening research. In recent years, many domestic scholars have also used schema theory to English listening comprehension research and achieved fruitful results (Zhou, 2002; Feng, 2001). Their research showed that schema theory can help improve listening comprehension. But according to statistics of the author, among 80 articles that study the relation between the schema and listening comprehension, most of which belong to theoretical discussion of critical thought, only a few of which belong to empirical quantitative research articles (Huang, 1998; Li, 2005). These articles' empirical study focused on the confirmation of the influence of background knowledge on listening comprehension through the contrast of familiarity degree and almost didn't involve the influence of the input of background knowledge on listening comprehension. Based on schema theory, the author designs an English listening teaching mode, applies quantitative and qualitative methods to analyze the influence of background schema knowledge on listening comprehension and its role in the English listening teaching for English majors and tries to explore an effective listening teaching mode for them.

\section{Theoretical Framework}

\subsection{Schema Theory}

British psychologist Bartlett (1932) who used the term of schema in his classic works Remembering. "Schema" refers to an active organization of past reactions, or of past experiences, which must always be supposed to be "operating in any well-adapted organic response." (Bartlett, 1932, p. 201) For Bartlett, the fact that a schema is, as he calls it "influenced by the past" (p. 202) is crucial for his study. Schemata, as Bartlett shows are the structures that the constructive activity of memory is based on. In this book, he points out that people's memorizing is able to organize various information and experiences into cognitive structure and to form conventional schemata, which are stored in their memory. Compared with those schemata, the new experience can be understood. Bartlett noticed that lots of the recalls were not precise, but involved the replacement of unfamiliar information with something more familiar. He also found that majority of inferences that went beyond 
the information given in the original text. In order to interpret these findings, Bartlett considered that people had schemata, or unconscious mental structures that could represent an individual's generic knowledge about the world. It was through schemata that old knowledge influences new information. Yule (2000) held the same belief and he considered that a schema was a general term for a conventional knowledge structure which remained in memory. Carrel (1983) put forward modern schema theory, defined the schema as the previous knowledge framework. He thought that schema was a kind of abstract knowledge structure used by listener or readers to understand a discourse. Schema is the foundation of cognition, is the organic whole of background knowledge. Once the schema is formed in brains, it will reorganize, understand and memorize the information gained later (Zhou, 2002). In all, the schema is the storage of past gained knowledge in brains, is the "original stored knowledge" or "background knowledge".

\subsection{Schema Theory-based Listening Comprehension Mode}

In listening teaching, schema can be divided into linguistic schema and content schema. Carrell \& Eisterhold (1988, p. 79) claimed linguistic schema was the listener's existing linguistic knowledge, for examples, phonetics, lexis, grammar and so on. In other words, linguistic schema contains language information in the materials, which played a basic part in a comprehensive understanding of the context. Content schema is also known as topic schema. Carrell \& Eisterhold (1983) illustrated that content schema referred to people's own background knowledge about the topic and provided people with a foundation, a basis for comprehension. In other words, content schema refers to the background information that is related to "theme" and "cultural and social knowledge" and it reflects the learners' degree of familiarity to listening material. These two kinds of listening comprehension mode are characterized by "bottom-up" and "top-down" modes. "Bottom-up" means that listener begin with the most basic language knowledge, from words to phrases, to sentence, and to discourse. That is to say, phonetic units are decoded and combined together to form words, words are combined together to form phrases, phrases were combined together to form utterances, and utterances are combined to form complete meaningful text. It is a gradual process, a process which is from the part to the whole. "Top-down" refers to listeners using the existing abstract concept in brain and background information to analyze the new input information, make prediction and inference to the article, and understand the articles. This is a process which is from the whole to the part. Godman (1971) asserted that listeners utilized their prior knowledge to expound the discourse as well as created possible expectations of what they would hear in top-down processing. Top-down mode is sometimes thought as macro information processing, in which listeners often activate the schematic knowledge stored in brain. This is a process which is from the whole to the part. In listening practice, listeners should combine these two processes, and teachers should apply them alternately in English listening teaching in order to enhance students' listening ability, for these two modes complement with each other and interact with each other. In the traditional listening teaching, teachers often adopt "bottom-up" mode based on the linguistic schema. However, the teaching effect is not ideal. It is difficult to improve students' listening level. Therefore how to highlight the status of background knowledge in listening teaching and how to design a better listening teaching mode based on the schema theory is the problem that is worth thinking over.

\subsection{Schema Theory-based Listening Teaching Mode for English Major}

Underwood (1990) pointed out: a better listening mode should be divided into three stages, pre-listening stage, while-listening stage and post-listening stage. Based on the theory of "three stages" of Underwood and combining with the basic principle of schema theory, the author put forward listening teaching mode for English majors.

The following are the specific teaching designs:

\subsubsection{Teaching Design for Pre-Listening Stage}

Pre-listening stage is the preparation stage. Teachers at this stage should activate students' existing schemata and help them build new schema.

\section{1) Activate students' existing schemata}

The activation of schemata indicates that learners make an inference to relevant background knowledge according to some information in listening materials, for example, key titles, and keywords. In daily study and life, students have accumulated experience and background knowledge relevant to social culture, science and technology. As to a lot of listening material, there are many relevant schemata existing in their brains. The key is how to activate them and improve the students' understanding ability effectively. Her is an example from College English Listening Course, book one, unit 2. The theme of the unit is "weather". In the teaching process, the author first asked students to speak out the words that are related to the weather. All of the students described 
the weather actively and enthusiastically. Then the author led them to associate the weather with areas so as to activate their geographical knowledge. Students have schemata concerning weather and areas before listening, which relived their anxiety. When hearing the related listening material, they could manage to understand it better.

2) Help students to build the new schemata

Students' schemata in their brain are limited. It is necessary for teachers to help students build more schemata to enrich students' schema knowledge. Before classes, teacher can ask students to collect background knowledge concerning the theme of listening materials through network resources, library resources, and reading extracurricular books. Teachers can also directly introduce relevant background knowledge in classroom to help students set up new schemata. There is another example from College English Listening Course, book two, unit 3. This is a listening material about the compulsory education in England. The background knowledge relevant to examination and education in their education system is very different from us. For example, CCSE, A-level, six-formers, that knowledge sounds very confusing. But after the author introduced the background knowledge of British education and examination, students soon understood. In addition, teachers can organize students to have an open discussion. The schemata in students' mind sometimes are the same and sometimes are the different. Through discussion and communication, the schemata in their minds are enriched and improved, achieving better schema effects.

\subsubsection{Teaching Design for While-Listening Stage}

Listening comprehension is the most important stage in the whole process of listening comprehension. At this stage teachers should cultivate students to utilize the interactive mode of listening comprehension. First of all, the teacher can apply "top-down" strategy to guide the student to understand the article on the whole. For examples, asking students to answer questions and state the general idea in order to understand the article in general, instead of putting emphasis on individual new words or difficult sentences; secondly, teacher can apply "bottom-up" strategy to guide students to listen intensively, and ask them to identify important detailed information. In the meanwhile teachers can ask students to finish exercises relevant to details after intensive listening. After the last listening, teachers can ask students to use "top-down" strategy to check or revise the prediction that is made before listening. In addition, at this stage, teachers should guide students to use some listening strategies, such as: taking notes, grasping key words, concentrating selectively, predicting and associating in order to fasten the understanding and memorizing of the listening materials, improve students' listening comprehension ability effectively.

\subsubsection{Teaching Design After-Listening Stage}

In traditional English listening teaching for English majors, teachers usually don't organize students to review the background knowledge concerning listening materials at the end of the listening class. This listening teaching mode makes students miss the opportunity to consolidate the content schema. Actually, after-listening stage is the comprehensive exercising stage where schemata are consolidated and also the stage where students' ability of recalling and summarizing is trained. At this stage, teachers can take some measures to encourage students to retell the text, organize them to have a topic discussion, role playing, etc to help consolidate the new schema. Teachers can also consolidate and strengthen students' schemata by timely summarizing linguistic and cultural background knowledge concerning listening materials.

\section{Research Design}

\subsection{Research Questions}

This study aims to test schema theory-based teaching mode to prove effectiveness of listening teaching mode based on input of background knowledge, hoping to set up a set of effective English listening teaching modes. It tries to answer these questions:

(1) Can schema theory-based listening teaching mode increase listeners' background knowledge?

(2) Can schema theory-based listening teaching mode improve listeners' comprehension ability?

\subsection{Participants}

Second year English majors in average university took part in this research. Their attitude to listening test is more serious than other grade students because they were going to take part in test for English Majors-4, which assured the reliance of the test. Before research, we made a test on them and chose 60 students as the research objects. 30 students are in experimental group and 30 students are in controlled group. They had almost the same English level. Schema-theory based listening mode was used to experimental group and traditional listening 
teaching method was used to controlled group. Listening teacher of these two classes is the same.

\subsection{Research Instruments}

Research instruments mainly include: pre-experiment and post-experiment listening test paper, pre-experiment and post-experiment background knowledge test paper and post-experiment students' interview. The pre-experiment test paper and post-experiment test paper are all the real test paper for English majors-4, which ensured the reliability and validity of the experiment.

\subsection{Research Procedures}

The author did the experiment for a term. Before experiment, the author gave students a listening test to both experimental and controlled group. After 4-month experiment, author gave another listening test to these two groups. During the experiment, two groups used the same text book, had the same periods and were taught by the same listening teacher. In controlled group, teacher used traditional way to teach, that is, only explain new words, phrases and grammar, mainly asked students to listen intensively and didn't teach listening from text structure, background knowledge and cultural activities. After listening teacher only checked the answers and didn't specify the reasons. In experimental group, teacher organized teaching completely on schema theory-based teaching mode.

\subsection{Research Results and Discussion}

\subsubsection{Data Analysis of Students' Pre-Test and Post-Test Background Knowledge}

In order to know the background knowledge of the students, before experiment, the author organized a test for experimental group and controlled group. After 4-month experiment, the author organized another test for these two groups. Background knowledge test involves the customs and cultures of western countries, human geography knowledge of England and America. In order to know the level of background knowledge after a term's different teaching mode, a same test paper was used in pre-test examination and post-test examination. The whole score of the test paper is 50 .

Table 1. Pre-test and post-test result of background knowledge

Paired Sample Statistics

\begin{tabular}{llllll}
\hline group & $\begin{array}{l}\text { Pre-test of background } \\
\text { knowledge }\end{array}$ & $\begin{array}{l}\text { Post-test of background } \\
\text { knowledge }\end{array}$ & Increased range & T value & P value \\
\hline Experimental group & 36.23 & 40.05 & 3.82 & 2.713 & $.015^{*}$ \\
Controlled group & 36.05 & 37.18 & 1.43 & 1.238 & .108 \\
\hline
\end{tabular}

Note. P stand for significance level: ${ }^{*} \mathrm{P}<0.05 ; * * \mathrm{P}<0.01$.

Table 1 shows that after one-term listening teaching based on schemata, the background knowledge of experimental group has improved greatly, already reaching the level of significant difference on statistics $(\mathrm{P}=0.015<0.05)$, while background knowledge of controlled group has some improvement, but is far from the level of experimental group and fail to reach the level of significant difference $(\mathrm{P}=0.108>0.05)$. The scores of controlled group in post-test are much fewer than experimental group. So it proves that the new teaching mode of experimental group greatly benefit the increase of background knowledge.

\subsubsection{The Effect of Scheme Theory-Based Teaching Mode on Students' Listening Performance}

In order to know the changing of students' listening level, before experiment the author organized a listening test to the experimental group and controlled group. After experiment the author organized another test to these two groups. Test papers before and after experiment are all from past year test paper for English major-4. The author Uses paired sample T-test to check the scores of experimental group in order to find out what effects scheme theory-based teaching mode has on students' scores.

Table 2. Pre-test and post-test performance of experimental group

Paired Sample Statistics

\begin{tabular}{llllll}
\hline Scores & Mean & Standard deviation & Increased range & T-value & P-value \\
\hline Pre-test & 69.350 & 10.674 & & & \\
Post-test & 74.352 & 8.536 & 5.002 & 3.318 & $.004^{* *}$ \\
\hline
\end{tabular}

Note. P stands for significance level: $* \mathrm{P}<0.05 ; * * \mathrm{P}<0.01$. 
From the paired sample test (T-test) of table 2, we know after one term's of scheme theory-based teaching, average listening scores of experimental group are 74.35 , i5 points more than pre-experiment. Distinction of pre-test and post-test listening scores of experimental groups is obvious $(\mathrm{P}=0.004<0.01)$, which shows the new teaching mode has a positive effect on students' listening level. Post-test scores of controlled groups is higher than pre-test scores, but this difference is slight, see table 3.

Table 3. Pre-test and post-test performance of controlled group

Paired Sample Statistics

\begin{tabular}{llllll}
\hline Scores & Mean & Standard deviation & Increased range & T-value & P-value \\
\hline Pre-test & 69.250 & 10.465 & & & \\
Post-test & 70.461 & 8.438 & 1.211 & 1.038 & $.153^{* *}$ \\
\hline
\end{tabular}

Note. P stands for significance level: $* \mathrm{P}<0.05 ; * * \mathrm{P}<0.01$.

Besides, in order to compare whether theory-based teaching mode is more effective than traditional teaching, we also carry out independent sample T-test to analyze score difference of experimental group and controlled group in the post-test.

Table 4. Comparison of post-test scores of experimental group and controlled group

\begin{tabular}{llllll}
\hline Group & Mean & Standard deviation & Increased range & T-value & P-value \\
\hline Experimental group & 74.352 & 8.317 & & & \\
Controlled group & 70.736 & 10.015 & 3.616 & 2.403 & $.026^{*}$ \\
\hline
\end{tabular}

Note. P stands for significance level: $* \mathrm{P}<0.05 ; * * \mathrm{P}<0.01$.

Table 4 shows that post-test scores of experimental group is $74.35,3.62$ more scores than controlled group, 70.73 . Test scores of these two groups are of great difference. $(\mathrm{P}=0.026<0.05)$. Test scores of these two groups are of the same in pre-test, while test scores of these two groups in the post-test are of great difference. Besides, Experimental group's post-test scores are obviously higher than pre-test scores. That all indicates new teaching mode has a great impact on the performance of experimental group and scheme theory-based teaching mode is more effective than traditional teaching mode, for it can enhance students' listening performance and arouse students' interest in English. From schema theory we know, the more knowledge we store, the easier we understand the thing around us. That is to say, schema in listeners' mind is the main factor that affects listening understanding. Due to the fact that teachers activate relevant schemata of students, guide them to use listening strategies to predict information they will hear, direct them to focus their attention selectively, it seems to students that listening materials are no longer disorganized. This teaching mode helps students out of listening trouble, improve students' listening level effectively.

\subsubsection{Interview Analysis}

In order to test the effects of scheme theory-based teaching mode further, altogether 20 students were chosen to be interviewed from experimental group and controlled group, ten students from experimental group and ten from controlled group. Interview involved around three questions: (1) Have you listening level improved after 4-month study? (2) What do you think of your improvement? (3) Is background knowledge important to listening comprehension? To the first question, most of the interviewees gave positive answers. Three students in the controlled group said that their listening performance draw back a little because of the nervousness. Other students in controlled group said that their listening performance has enhanced more or less. Two students of the experimental group said that their listening performance was improved but the improvement falls behind the skill they learnt, and they would not fear the listening comprehension so much. The rest eight students believed that their listening performance had been improved greatly; they also achieved a lot of listening skills and background knowledge. All the ten students of the experimental group hold positive attitude towards schema theory-based listening mode and they believed they benefited a lot from it. Besides, they all thought the progress was due to obtaining a great deal of background knowledge and listening strategies. The new teaching mode gained their confidence toward listening learning and improved their listening ability and oral ability. Students of controlled group believed that their slight progress resulted from the improvement of their linguistic skills, they knew little about background knowledge and listening skills, and they still couldn't feel interested in listening learning. 
As for the importance of background knowledge in listening comprehension, ten students made it clear that background knowledge was one of the most important elements that affected listening comprehension, but students of controlled group didn't realize that. They thought the main factor that affected the listening comprehension was listeners' linguistic level, ignoring the grasp of background knowledge. Application research (Zhou, 2002) of schema theory-based listening teaching indicates that if listeners are short of background knowledge or apply it inappropriately, their listening comprehension will be affected severely. It is just that students of controlled group haven't relevant schemata that hindered their listening comprehension, but students of experimental group grasped many background schemata in their minds, which benefited them build new schemata and made them understand the listening materials correctly and thoroughly.

\section{Conclusion}

Quality and quantity research results of schema-based listening teaching mode for English majors show that this mode can help increase students' background knowledge and can help improve students' listening performance.

This study proved that effectiveness of teaching mode based on schema theory. Schema-based listening teaching can enhance students' enthusiasm and initiative in learning, fully exert the guiding role of the teacher in classroom and optimize the teaching efficiency. This teaching mode has some implications to English listening teaching, that is, teachers should endeavor to do the following: 1) Attach importance to background knowledge. Teachers should fully realize background knowledge is as important as linguistic knowledge. Teachers should change their old consciousness, paying too much attention to linguistic knowledge but show less interest in background knowledge. 2) Activate students' existing schemata. In the listening process, teacher should find every possible way to activate students' existing schemata knowledge, thus improve students' listening level.

However, schema based-listening teaching research is still in the stage of trial. Listening teaching mode based on schema theory need to be further improved and perfected. The author hopes that this research can bring up some beneficial references and thoughts for listening teaching. The author also wishes more colleagues will join in the discussion and research and do further empirical research to explore a more efficient and scientific teaching mode.

\section{References}

Barlet, F. C. (1932). Remembering: A Study in Experimental and Social Psychology. Cambridge: Cambridge University Press.

Carrell, P. L., \& Eisterhold, J. C. (1983). Schema Theory and ESL Reading Pedagogy. TESOL Quarterly, 17, 553-573. http://dx.doi.org/10.2307/3586613

Carrell, P. L., \& Eisterhold, J. C. (1988). Schema Theory and ESL Reading Pedagogy. In P. L. Carrell, J. Devine, \& D. E. Eskey (Eds.), Interactive Approaches to Second Language Reading. Cambridge University Press. http://dx.doi.org/10.1017/CBO9781139524513.010

Feng, Y. F. (2001). Schema Theory and English Listening Understanding. Jangsu Foreign Education Study, 1, 60-65.

Li, W. Y. (2005). Implication of Schema Theory to College English Listening Teaching. Foreign Linguistics and Literature, 3, 178-181.

Liu, S. L. (1996). Background Knowledge and Listening Strategies. Modern Foreign Language, 4, 29-33.

Underwood, M. (1990). Teaching Listening. New York: Longman.

Zhou, X. L. (2002). Application of Schema Theory in Listening Teaching. Foreign Language and Foreign Language Teaching, 2, 27-30.

\section{Copyrights}

Copyright for this article is retained by the author(s), with first publication rights granted to the journal.

This is an open-access article distributed under the terms and conditions of the Creative Commons Attribution license (http://creativecommons.org/licenses/by/3.0/). 